\title{
Research on the Cost Control with Hotel Operation System Based on Cost Management Theory
}

\author{
Guo Zhiying ${ }^{1,2, *}$ \\ ${ }^{I}$ Shanghai University of Finance and Economics, Shanghai, China; ${ }^{2}$ School of Economics \& Management, Shanghai \\ Maritime University, Shanghai, China
}

\begin{abstract}
The important task in hotel management is to control the food cost and provide good service. The cost and the expenses in the hotel cover a wide range, concern many fields, and also face the challenge from many unpredictable factors. In this paper, a new method is developed as to the control difficulties in the costs control of food, and with the help of personal experience. Through impartial analysis of the food cost rate in test time, the food cost rate can be control in the target by find and solve the problems in cost control work with careful observation, timely improvements. Some advices are provided to the managers. Under these advices, cost control would be effective, and the hotel profits increase smoothly.
\end{abstract}

Keywords: Cost control, food cost rate, hotel management, profit.

\section{INTRODUCTION}

Food is god to the people, China in high-speed development, the dining industry develops of growth power the head is sturdy. In recent years, China's consumer food service market has increased significantly because of the China's economic growth [1]. Restaurant industry is developing rapidly because of the broad market potential, as well as the food and restaurant industry has low barriers to entry, and flexible business model, industry advantages of higher yields.

In 2003 dining industry retail sum is $500,000,000,000$ dollars [2], 2006 already more than 1,according to Chinese cooking association estimate, attain 3 dollars till 2012, the dining industry has become to the society economy and society develop the profession of producing the important influence $[3,4]$. Follow of be in great quantities schedule to and settle accounts an information will make the unbearable heavy burden of staff member of dining industry, and the ineluctability will appear this or mistake like that.

However, our country's high-end food industry has been stroked seriously because of the slowdown of the economic growth in China, raw material prices, labor costs, rents and other operating costs rise and the central government contained the luxury consumption and so on. Hotel industry has not been spared [5]. And its development faces too many new obstacles. Its sales revenue, gross margin and net growth levels had significantly lower interest rates. To steady and healthy development of enterprises, and improve the comprehensive competitiveness of enterprises, hotel industry urgently need to improve its cost control [6].
Due to the limited level of management, there exist some draw backs in the understanding of cost management and control system. Under the situation of globalization, the current cost control system needs to be improved for more competitive advantage [7].

At Present, there is just a petty profit in hotel industry. In order to pursue competitive advantage and bigger development space in the narrow market space, the enterprise must reduce the cost and expenses by applying strategic management means [8]. The profit of the enterprise depends mainly on the managing cost and the expenses control. Hence, it is indispensable for the enterprise to efficiently control the managing cost and the expenses in order to succeed in management.

\section{COST-ACCOUNTING METHODS}

\subsection{Food Cost Rate}

Daily cost management in hotels is to determine the reasonableness of the cost of catering based on the food cost rate [9]. Food cost rate is an important parameter for food service enterprises.

$\mathrm{c}=\mathrm{s}_{f}+m_{g}-m_{t}-\mathrm{s}_{1}$

$\mathrm{C}$ is the food cost; $\mathrm{S}_{f}$ is the food stocks of the first day in this mouth. $\mathrm{m}_{\mathrm{g}}$ is the material get from storeroom this mouth. $m_{t}$ is the material transferred out. $S_{1}$ is food stocks of the last day of the mouth.

$r_{c}=c / i_{o}$

$r_{c}$ is the food cost rate. $i_{o}$ is the operating income of the day.

2015 Bentham Open 


\subsection{Food Cost Rate in the Month}

According to the construction of sale income, food cost rate is divided to six types: dish, wine, drink, tea, cigarette, others. Calculate the actual food rate of each type in this month.

$r_{m}=c_{s} / i_{s}$

$r_{\mathrm{m}}$ is the food cost rate in the month. $\mathrm{C}_{\mathrm{s}}$ is the sale cost. $i_{s}$ is the sale income.

\subsection{Formulate the Standard of Food Cost Rate}

In data statistics, it shows that the food cost rate is between $35 \%$ and $40 \%$ in four-star hotel, between $40 \%$ and $45 \%$ in three-star hotel [10]. The more stars of the hotel, the lower food cost rate. To formulate the standard of food cost rate is important to measure actual cost in the hotel. The management should determine the standard of food cost rate in line with average food cost rate in hotel industry and history food cost rate of the hotel. And then the standard should be release to other department as assessment indicators in budgeting.

\subsection{Analyze Food Cost Rate in the Mouth}

In the last day of the mouth, actual food cost rate should be reported to the managers by finance department. The chef leader and accountant charging cost analyze the result of actual food cost rate, compared with food cost rate in budgeting. If there is a huge difference, the managers should search the reason in the kitchen and storehouse, and solve the problems. Meanwhile they should report these problems and solutions in budget analysis to leader. Through the leaders, the director of hotel is advised to solve the abnormal and inefficient problems in business process, and to strength management of food cost.

\subsection{Compare the Actual Food Cost Rate with Standard Food Cost Rate}

Standard cost of hotel is a ruler to account the food cost. Comparing the actual food cost with standard cost, we can solve the problems that find in the report, and control the cost of hotel. Because of large computation in comparing the actual food cost with standard cost, so a new method is proposed. The actual food cost rate in a period is chosen to formulate the standard of food cost rate. Then, comparing the actual food cost with the standard cost of this period which called test time standard cost, the differences of food costs are analyzed.

The test time standard cost is shown as following:

$\mathrm{c}_{\mathrm{f}}=\frac{\sum_{i=1}^{n} S_{i} p_{i}}{\sum_{i=1}^{n} S_{i}}$

$c_{f}$ is the food cost. $i$ is a kind of food. $s_{i}$ is the sale of food $i . p_{i}$ is the price of food $i$.

$c_{d}=\frac{\sum_{i=1}^{n} c_{f i} a_{i}}{\sum_{i=1}^{n} a_{i}}$

$\mathrm{C}_{\mathrm{d}}$ is the cost of dishes. $\mathrm{C}_{\mathrm{fi}}$ is the food cost of the food in the dish. $\mathrm{a}_{\mathrm{i}}$ is the amount of the food in the dish.

$r c_{\mathrm{d}}=\frac{\sum_{i=1}^{n} c_{d i}}{S}$

$r c_{d}$ is the cost rate of dishes. $c_{d i}$ is the cost of dishes $S$ is the sale of the dishes.

\section{COST-ACCOUNTING ANALYSIS AND RESULTS IN A HOTEL}

\subsection{Comprehensive Cost Analysis}

In the control of actual hotel cost, the data of income and cost in the January to April of 2013 is added and refined totally. It is shown in Tables 1-4.

Table 1. Cost category of January.

\begin{tabular}{|c|c|c|c|}
\hline & Income & Cost & Cost Rate \\
\hline \hline Dish & 127437.24 & 51572.40 & $40.47 \%$ \\
\hline Wine & 69203.23 & 35822.50 & $51.76 \%$ \\
\hline Drink & 1934.50 & 1024.90 & $52.98 \%$ \\
\hline Tea & 7003.08 & 2034.65 & $29.05 \%$ \\
\hline Cigatette & 14872.33 & 12498.50 & $84.04 \%$ \\
\hline Other & 7521.15 & 1039.45 & $13.82 \%$ \\
\hline Total & 227971.5 & 103992.4 & $45.62 \%$ \\
\hline
\end{tabular}


Table 2. Cost category of February.

\begin{tabular}{|c|c|c|c|}
\hline & Income & Cost & Cost Rate \\
\hline \hline Dish & 966158.56 & 432012.85 & $44.71 \%$ \\
\hline Wine & 140450.32 & 45487.80 & $32.39 \%$ \\
\hline Drink & 2114.96 & 1634.20 & $77.27 \%$ \\
\hline Tea & 7093.32 & 1542.35 & $21.74 \%$ \\
\hline Cigatette & 11577.59 & 11239.80 & $97.08 \%$ \\
\hline Other & 6006.20 & 2809.20 & $46.77 \%$ \\
\hline Total & 1133400.95 & 494726.2 & $43.65 \%$ \\
\hline
\end{tabular}

Table 3. Cost category of March.

\begin{tabular}{|c|c|c|c|}
\hline & Income & Cost & Cost Rate \\
\hline \hline Dish & 636723.22 & 307903.58 & $48.36 \%$ \\
\hline Wine & 43982.96 & 22376.50 & $50.88 \%$ \\
\hline Drink & 1333.58 & 1033.55 & $77.50 \%$ \\
\hline Tea & 7234.45 & 1368.89 & $18.92 \%$ \\
\hline Cigatette & 10283.23 & 9831.57 & $95.61 \%$ \\
\hline Other & 6492.55 & 2466.60 & $37.99 \%$ \\
\hline Total & 764539.99 & 344980.69 & $45.12 \%$ \\
\hline
\end{tabular}

Table 4. Cost category of April.

\begin{tabular}{|c|c|c|c|}
\hline & Income & Cost & Cost Rate \\
\hline \hline Dish & 611587.65 & 289401.81 & $47.32 \%$ \\
\hline Wine & 40541.53 .96 & 15736.20 & $38.81 \%$ \\
\hline Drink & 845.35 .84 & 737.21 & $87.12 \%$ \\
\hline Tea & 7621.56 & 1344.41 & $17.64 \%$ \\
\hline Cigatette & 12276.37 & 8345.53 & $67.98 \%$ \\
\hline Other & 5429.41 & 1645.30 & $30.30 \%$ \\
\hline Total & 678303.67 & 317210.46 & $46.77 \%$ \\
\hline
\end{tabular}

First, we analyze the comsuming and sale of products which can be used afer easy machining.

It is not so complicated of the hotel cost control. Through good method, we can get the point of. There are many problems that caused by low quality of staff and bad managmet, after analysis of Table. So, the management of storeroom and kitchen should be strengthened.

Second, analysis of actual cost rate, standard cost rate, budgeting cost rate.
The average price of each materials in June is chosen. By the new method, the standard cost database is set. And getting the sale data, we analyze the price and sale income of each dish. After list the sale income and sale amount, the food cost data of test time is gotten.

According to classification of the food cost data, we get the report of food cost. In the next analysis, the dishes and materials are divided in to these types: pork, beef, lamb, chicken, duck, fish, shrimp, geese, dog, vegetable, rice, soup. 
Table 5. Analysis table of standard food cost.

\begin{tabular}{|c|c|c|c|c|c|}
\hline & Sale & $\begin{array}{c}\text { Standard Cost } \\
\text { Amount }\end{array}$ & Standard Cost Rate & Actual Cost Rate & Budgeting Cost Rate \\
\hline Pork & 54874.14 & 29501.26 & $53.76 \%$ & & \\
\hline Beef & 23457.18 & 15004.57 & $63.97 \%$ & & \\
\hline Lamb & 36249.30 & 17261.88 & $47.62 \%$ & & \\
\hline Chicken & 22398.50 & 13595.40 & $60.70 \%$ & & \\
\hline Duck & 6690.30 & 2971.33 & $44.41 \%$ & & \\
\hline Fish & 26271.75 & 10328.99 & $39.32 \%$ & & \\
\hline Shrimp & 13666.60 & 7122.46 & $52.12 \%$ & & \\
\hline Geese & 120.00 & 66.00 & $55.00 \%$ & & \\
\hline Vegetable & 45993.20 & 15600.95 & $33.92 \%$ & & \\
\hline Rice & 3960.40 & 2091.38 & $52.81 \%$ & & \\
\hline Soup & 3280.60 & 808.22 & $24.64 \%$ & & \\
\hline Total & 236962 & 114352.4 & $48.26 \%$ & $46.12 \%$ & $44 \%$ \\
\hline
\end{tabular}

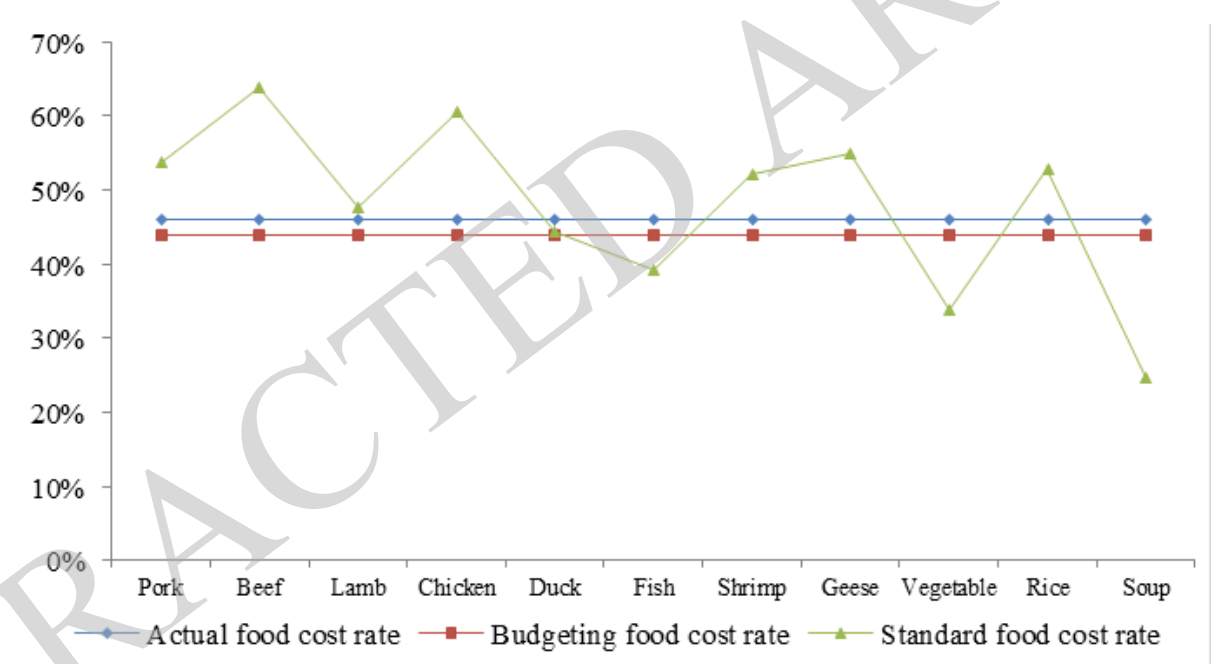

Fig. (1). The rate of categories food costs comparision chart.

The standard food cost is not so accurate, which influence the judgment of sales. The price of dishes is not good, because it is not connected with material price strongly. The gross margin on each dishes needs to measure further with more data. The grade of three levels of the dinner should be widened, with accurate location. These problems show in Table 5.

As the standard of star hotel, the food cost rate is between $30 \%-40 \%$. But the food coat rate in this hotel is much higher because of improper cost control, shown in Fig. (1).

Gathering the dishes sale in one day, sale cost of each dish is calculated.

In the difference analysis, $53 \%$ is out of budgeting, only $47 \%$ in control. And it is major in pork, beef, lamb, chicken, with big sales, shown in Fig. (2).
Problems are found in the differences analysis:

1. Much more materials are accumulated in kitchen instead of storeroom.

2. The component of dishes are out control, wasting in producing.

3. There are errors in procurement and acceptance.

4. The prices of materials are changing fast.

5. in the dishes of good sale, the profit is not high enough, and the unpopular dishes need change.

\subsection{Food Cost Control}

So some advice can be provided through this new analysis method of food cost in hotel, according to the result. 


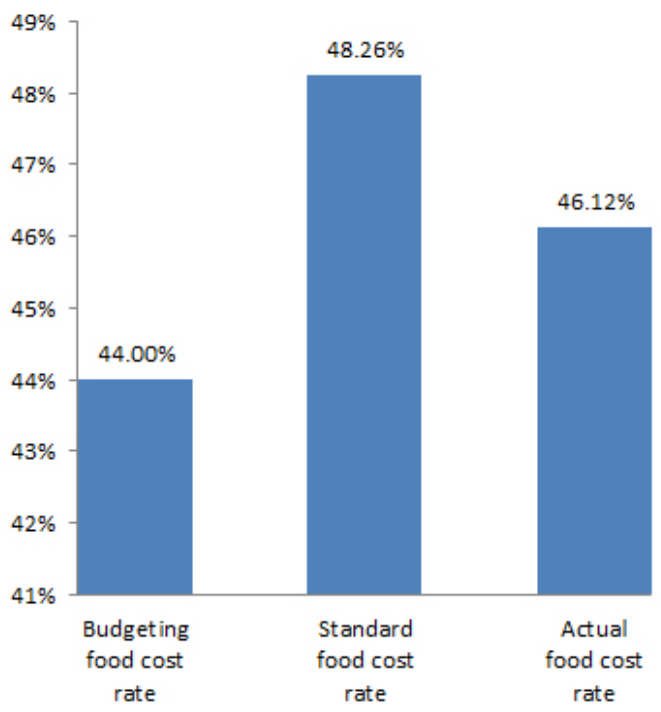

a: Comparison chart of Food cost rate

Fig. (2). Food cost rate and sales structure analysis.

First, subtotal the cost of dishes every 2 weeks. Report the cost control in the meeting.

Second, check the stock, returns of storeroom at the end of month. Analyze month cost report.

Third, looking for reasons of these question: what is the unpopular dish and why; how to add the profit of popular dishes.

Forth, the use of information technology tools and improve management efficiency and effectiveness.

Fifth, the internal audit needs to play an important role of cost control.

\section{CONCLUSION}

The important task in hotel management is to control the food cost and provide good service. In this paper, a new method is developed for food cost control of the hotel. Through impartial analysis of the data in the method, the food cost rate can be control in the target by find and solve the problems in cost control work with careful observation, timely improvements. In effective cost control, the hotel profits increase smoothly, and the operating is better and better.

\section{CONFLICT OF INTEREST}

The author confirms that this article content has no conflict of interest.

\section{ACKNOWLEDGEMENTS}

Declared none.

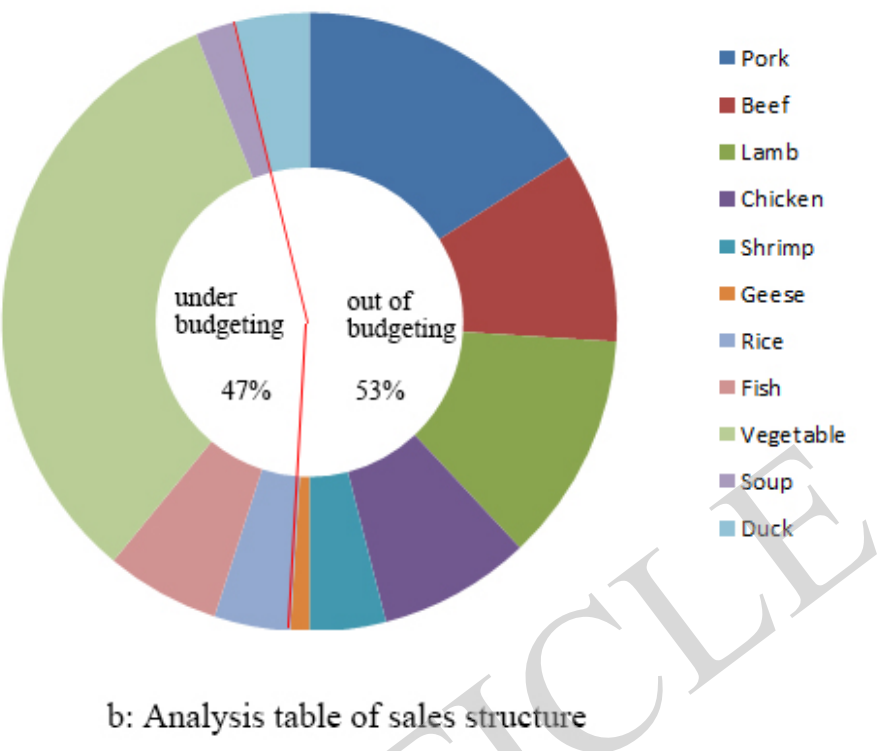

\section{REFERENCES}

[1] L.H. Chung, and L.D. Parker, "Integrating hotel environmental strategies with management control: a structuration approach" Business Strategy and the Environment, vol. 17, no. 4, pp. 272-286, 2008.

[2] C,Z.M. Jamil, and R. Mohamed, "The effect of management control system on performance measurement system at small medium hotel in Malaysia", International Journal of Trade, Economics and Finance, vol. 4, no. 4, pp. 202-208, 2013.

[3] J.C. Lam, and W.W. Chan, "Life cycle energy cost analysis of heat pump application for hotel swimming pools", Energy Conversion and Management, vol. 42, no. 11, pp. 1299-1306, 2006.

[4] D. Lamminmaki, "Accounting and the management of outsourcing: An empirical study in the hotel industry", Management Accounting Research, vol. 19, no. 2, pp. 163-181, 2008.

[5] M. Vij, "A survey of factors influencing cost structures in the Indian hotel sector", Worldwide Hospitality and Tourism Themes, vol. 4, no. 5, pp. 449-462, 2012.

[6] O. Pavlato and I. Paggios, "Management accounting practices in the Greek hospitality industry" Managerial Auditing Journal, vol. 24, no. 1, pp. 81-98, 2008.

[7] T. Simons, and T. Hinkin, "The effect of employee turnover on hotel profits a test across multiple hotels", Cornell Hotel and Restaurant Administration Quarterly, vol. 42, no. 4, pp. 65-69, 2005.

[8] R. Sainaghi, P. Phillips and V. Corti, "Measuring hotel performance: Using a balanced scorecard perspectives' approach", International Journal of Hospitality Management, vol. 34, pp. 150-159, 2013.

[9] R.S. Schmidgall, and J.D. Ninemeier, "Budgeting in hotel chains: coordination and control", Cornell Hotel and Restaurant Administration Quarterly, vol. 28, no. 1, pp. 78-84, 1987.

[10] M. Vij, "A survey of factors influencing cost structures in the Indian hotel sector', Worldwide Hospitality and Tourism Themes, vol. 4, no. 5, pp. 449-462, 2012.

Received: June 10, 2015
(C) Guo Zhiying; Licensee Bentham Open.

Revised: July 29, 2015

Accepted: August 15, 2015

This is an open access article licensed under the terms of the (https://creativecommons.org/licenses/by/4.0/legalcode), which permits unrestricted, noncommercial use, distribution and reproduction in any medium, provided the work is properly cited. 